\title{
PER ASPERA AD ASTRA: К ЮБИЛЕЮ АРМАНА БЕЙСЕНОВА
}

\section{(C) 2020 г. Марина Васильевна Бедельбаева ${ }^{1}$, Галия Аппазовна Базарбаева ${ }^{2}$}

\begin{abstract}
${ }^{1}$ кандидат исторических наук, заведующая музеем археологии и этнографии, Сарыаркинский археологический институт, НАО «Карагандинский университет имени академика Е. А. Букетова», г. Караганды, Казахстан. E-mail: bmv_1967@mail.ru ${ }^{2}$ кандидат исторических наук, ведущий научный сотрудник, Институт археологии им. А. Х. Маргулана, г. Алматы, Казахстан. E-mail: galiya2002@gmail.com
\end{abstract}

Аннотация. В сентябре исполнилось 60 лет казахстанскому археологу, специалисту в области изучения древностей раннего железного века Центральной Азии - Арману Бейсенову. Адресуя данную статью в его честь, отметим, что под руководством Армана Зияденовича сделан ряд открытий в области изучения памятников эпохи бронзы, раннего железного века и Нового времени Сарыарки и Жетысу. Благодаря А. З. Бейсенову, были изданы сборники документов и научных статей, монографии. Особенного внимания в творчестве коллеги заслуживает достойное отношение к наследию классиков отечественной археологии. Благодаря кропотливому труду А. 3. Бейсенова, очерчены силуэты казахстанских археологов XX в., чьи работы актуальны и востребованы в настоящее время. В настоящее время А. З. Бейсенов успешно продолжает исследования, совмещая экспедиционную и кабинетную работу, занимается подготовкой молодых специалистов, разрабатывает актуальные направления отечественной науки. Хронологическая колонка 14С дат по исследованным А. 3. Бейсеновым памятникам в археологии раннего железа Казахстана, пожалуй, не знает себе равных. От всей души поздравляем юбиляра и желаем стремления к новым открытиям, достойных учеников, реализации задуманного!

Ключевые слова: археология, А. З. Бейсенов, наука, ранний железный век, наследие классиков отечественной археологии, издания

\section{PER ASPERA AD ASTRA: АРМАН БЕЙСЕНОВТЫН МЕРЕЙТОЙЫНА}

\section{Марина Васильевна Беделбаева ${ }^{1}$ Ғалия Аппазқызы Базарбаева}

${ }^{1}$ тарих ғылымдарының кандидаты, археология және этнография музейінің меңгерушісі, Сарыарқа археология институты, академик Е. А. Бөкетов атындағы Қарағанды университеті Қарағанды қ., Қазақстан. E-mail: bmv_1967@mail.ru

2 тарих ғылымдарының кандидаты, жетекші ғылыми қызметкер, Ә. Х. Марғұлан атындағы Археология институты Алматы қ., Қазақстан. E-mail: galiya2002@gmail.com

Аннотация. Қыркүйек айында қазақстандық археолог, Орталық Азияның ерте темір дәуірін зерттеу бойынша белгілі маман - Арман Бейсенов 60 жасқа толды. Осы мақаланы оның құрметіне арнай отырып, Арман Зияденұлының жетекшілігімен Сарыарқа мен Жетісудың қола дәуіріне, ерте темір ғасыры мен жаңа кезеңіне қатысты ескерткіштерді зерттеу барысында бірқатар жаңа ашулар болғандығын атап өткіміз келеді. А. 3. Бейсеновтің жетекшілігімен құжаттар мен мақалалар жинағы, монографиялар басылып шықты. Әріптесіміздің шығармашылығындағы отандық археологияның 
классиктерінің мұрасына деген құрметі ерекше назар аудартады. А. З. Бейсеновтың маңдай терін төгіп жасаған еңбегінің арқасында қазіргі таңда жұмыстары өзекті және сұранысқа ие болып отырған XX ғ. қазақстандық археологтардың бейнесі жасалынды. Қазіргі сәтте А. 3. Бейсенов экспедиция мен кабинеттік жұмысты табысты ұштастыра отырып өз зерттеулерін жалғастыруда, жас мамандарды дайындауда, отандық ғылымның өзекті бағыттарын жетілдіруде. А. 3. Бейсеновтың зерттеулері бойынша Қазақстанның ерте темір археологиясының ескерткіштерінің 14С хронологиялық бағанына тең келетіні табыла қоймайды. Мерейтой иесін шын жүректен құттықтай отырып, жаңа ашуларға ұмтылулар мен лайықты шәкірттер болуын, ойға алғандарын жүзеге асыра беруіне тілектеспіз!

Түйін сөздер: археология, А. З. Бейсенов, ғылым, ерте темір ғасыры, отандық археологияның классиктерінің мұрасы, басылым

\title{
PER ASPERA AD ASTRA: TO THE ANNIVERSARY OF ARMAN BEISENOV
}

\author{
Bedelbayeva Marina V. ${ }^{1}$, Bazarbayeva Galiya A. ${ }^{2}$
}
${ }^{1}$ Candidate of Historical Sciences, Head of the Museum of Archeology and Ethnography, Saryarka Archaeological Institute, Academician E. Buketov Karagandy University, Karagandy, Kazakhstan. E-mail: bmv_1967@mail.ru
${ }^{2}$ Candidate of Historical Sciences, Leading Researcher, A. Kh. Margulan Archeology Institute, Almaty, Kazakhstan. E-mail: galiya2002@gmail.com

\begin{abstract}
In September, a Kazakh archaeologist, specialist in antiquities of the Early Iron Age of Central Asia, Arman Beisenov, turned 60. Dedicating this article to him, we should note that under the leadership of Arman Z. Beisenov a number of discoveries have been made whyle studying the sites of the Bronze Age, Early Iron Age and the modern history of Saryarka and Jetysu. By the effort of A. Z. Beisenov, collections of documents, scientific papers and monographs have been published. His respectful attitude towards the body of work of the pioneers of national archaeology in his studies deserves a special attention. Owing to the painstaking work of A. Z. Beisenov, the silhouettes of Kazakh archaeologists of the $20^{\text {th }}$ century, whose works are still relevant and in demand at present, have been redefined. Currently, A. Z. Beisenov successfully carries out new investigations, combining field work and desk research, engaging young specialists, and developing topical areas of national science. The set of 14C dates from the Early Iron Age sites studied by A. Z. Beisenov in Kazakhstan is, perhaps, second to none. We sincerely congratulate A. Z. Beisenov and wish him to strive for new discoveries, worthy students, and achievement of his ambitions!
\end{abstract}

Keywords: archaeology, A. Z. Beisenov, science, Early Iron Age, the heritage of classics of national archaeology, publications

\section{Введение}

Среди ярких открытий первого десятилетия ХXI в., сделанных в области исследования памятников раннего железного века Казахстана, можно с уверенностью назвать успехи, достигнутые в изучении Каркаралы края, сыгравшего в истории Отечества важную роль. Именно здесь и родился Арман Бейсенов - археолог,

выпускник исторического факультета Карагандинского университета (1987 г.), кандидат исторических наук (1997 г.), в 2011-2013 гг. заместитель директора по науке Института археологии им. А. Х. Маргулана, заведующий отделом первобытной археологии, в настоящее время директор Научно-исследовательского 
Бедельбаева М.В., Базарбаева Г.А. Per aspera ad astra: к юбилею Армана Бейсенова

центра истории и археологии «Бегазы-Тасмола», автор и соавтор более 10 монографий и свыше 400 научных, научно-справочных статей. Публикации А. З. Бейсенова позволяют представить актуальность разрабатываемых им проблем и направлений исследовательской деятельности. Именно поэтому юбилейная статья связана с анализом его научного творчества.

Еще в студенческие годы Арман Бейсенов совместно с Ж. Е. Смаиловым участвовал в исследованиях Кызылкентского дворца (1986-1987 гг.), совместив работу в поле и последующий поиск письменных источников, проливающих свет на историю строительства и существования этого джунгарского памятника. Впервые в науке был аргументирован тезис об основании храма представителем ойратской знати Кундолон-Убаши [Смаилов, Бейсенов, 1996; 2004]. Впоследствии расширенная статья вошла в коллективную монографию «Восточная Сарыарка. Каркаралинский регион в прошлом и настоящем», которая, пожалуй, не имеет аналогов в научной литературе, как по своей информационной полноте, так и хронологическому охвату [Восточная Сарыарка, 2004]. Это издание принадлежит к числу несомненных заслуг А. 3. Бейсенова, который совместно с К. С. Алдажумановым был редактором этой публикации и внес вклад в написание практически всех разделов книги. Монография обобща- ет огромный фактический материал и подводит итог многолетним исследованиям и дискуссиям по ряду проблем. В ней под различными углами зрения освещены история, демография, социология, экономика, этнография, топонимика и др. Книга содержит много таблиц, рисунков, схем, карт, фотографий, архивных материалов. Монография читается с неподдельным интересом: абсолютно научная профессиональная (а не научно-популярная!) книга понятна и доступна не только узкой аудитории специалистов, но и широкому кругу читателей.

В этом же 2004 г. была выпущена «Археологическая карта Каркаралинского района» с максимально полным охватом и характеристикой памятников древности и средневековья, одним из авторов которой является А. 3. Бейсенов [Археологическая карта..., 2004]. Логическим продолжением в региональных исторических исследованиях стал выпуск книг из серии «Каркаралинская история», где впервые опубликована представительная серия архивных документов. А. 3. Бейсенов выступает в качестве

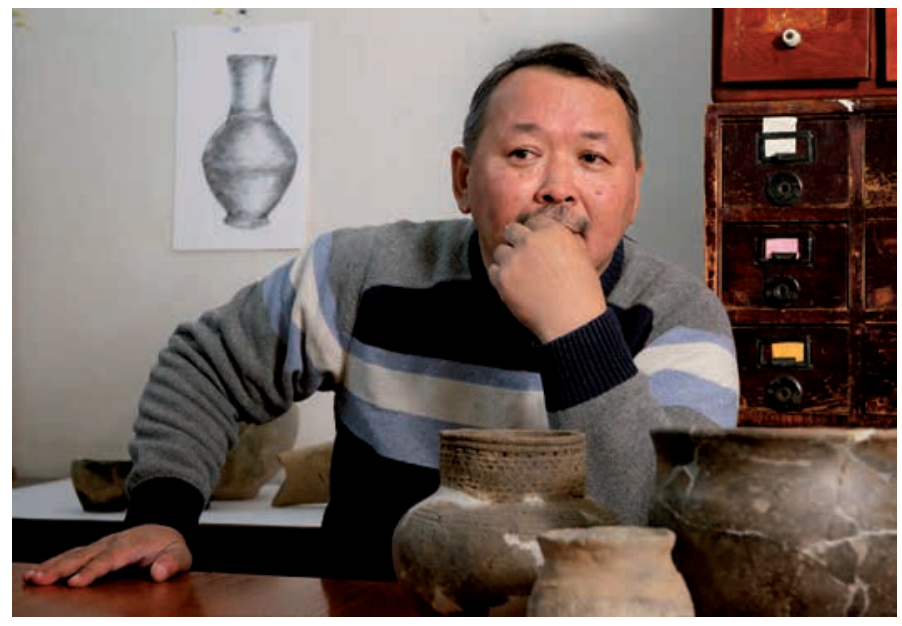

Арман Бейсенов. Фото Н. Постникова Arman Beisenov. Photo by N. Postnikov 
составителя и ответственного редактора (совместно с К. С. Алдажумановым) [История Каркаралы..., 2008; 2009].

Опыт по изданию книг в полной мере реализовался в период, когда А. 3. Бейсенов занимал должность заместителя директора Института археологии им. А. Х. Маргулана. В год празднования 20-летия обретения независимости Республики Казахстан увидели свет трехтомник конференции «Археология Казахстана в эпоху независимости: итоги, перспективы» [2011], а также два сборника «Свидетели тысячелетий: археологическая наука Казахстана за 20 лет (1991-2011)» [2011] и «Сакская культура Сарыарки в контексте изучения этносоциокультурных процессов степной Евразии» [2011], в которых юбиляр выступил ответственным редактором.

А. 3. Бейсенов придает особое значение своевременному вводу в научный оборот результатов как полевых, так и аналитических исследований, и, благодаря его организаторскому таланту, были изданы монографии А. С. Ермолаевой [2012], Г. С. Джумабековой и Г. А. Базарбаевой [2013], И. В. Рудковского [2013] и многие другие.

Большое количество положительных отзывов было получено в адрес двухтомного сборника научных статей «Археологическое наследие Центрального Казахстана: изучение и сохранение» [2017], посвященного 70-летию организации первой археологической экспедиции Академии наук Казахстана. В сборнике нашли отражение различные моменты истории археологической науки нашей страны, обозначены перспективы новых исследований, а география и коллектив авторов красноречиво сви- детельствуют о масштабности проведенной работы.

\section{Изучение Тасмоль \\ Благодаря исследованиям} А. 3. Бейсенова значительно расширилась источниковедческая база Тасмолы. С конца 1980-х гг. и по сей день юбиляр плодотворно исследует памятники тасмолинской культуры в Центральном Казахстане. Основные положения и выводы по тасмолинской проблематике были сформулированы и опубликованы еще М. К. Кадырбаевым, который открыл наиболее яркие памятники (могильники на р. Шидерты - Тасмола I-VI и др.) и обосновал существование тасмолинской историко-этнографической общности (VII-VI вв. до н.э.), включающей регионы Центрального и Северного Казахстана, Южного Зауралья, исследовав вопросы хозяйства, культуры и этногеографии племен, представив типологию предметов вооружения, конского снаряжения, украшений и бытовой утвари [Кадырбаев, 1966, c. 304-433].

Анализируя в своей диссертации материалы более 170 погребальных памятников, А. 3. Бейсенов выделяет два типа сооружений, функционально отличающихся друг от друга. Это собственно погребальные памятники Тасмолы, воздвигнутые над захоронением умершего в виде надмогильного сооружения, и курганы с каменными грядами. Учитывая культурные особенности третьего хронологического этапа центральноказахстанской Тасмолы, А. 3. Бейсенов обосновал критерии выделения коргантасской культуры, которую датировал III-I вв. до н.э., соотнося с ним 22 захоронения [Бейсенов, 1997]. 
Бедельбаева М.В., Базарбаева Г.А. Per aspera ad astra: к юбилею Армана Бейсенова

В последующих исследованиях и публикациях автора источниковая база пополняется новыми памятниками (более 300), приводится описание инвентаря, статистические расчеты, спектральный анализ бронзовых изделий, данные краниологии [Бейсенов и др., 2015; Бейсенов, Хаврин, 2015; Beisenov et al., 2016; Бейсенов, 2018а]. В настоящее время вопросы происхождения, генезиса и дальнейших судеб памятников типа Коргантас - одна из дискуссионных проблем в изучении раннего железного века и ее решение позволит определить место тасмолинской культуры среди других культур скифо-сакской эпохи евразийских степей.

Исследование элитных курганов степной зоны Евразии пополнило количество материала по изучению процессов социальной дифференциации сакского общества. Впервые на широкой источниковой базе были проведены аналитические исследования и сделаны выводы о планиграфических особенностях насыпей элитных курганов сакской знати как архитектурных сооружениях, функционирующих не единовременно, а определенный, довольно длительный, хронологический период. Получена уникальная коллекция золотых изделий, выполненных в скифо-сакском зверином стиле, что позволило активизировать изучение происхождения искусства и вопросов семантики изобразительного ряда [Бейсенов и др., 2015], а также ряд важных проблем, связанных со статусом погребенных. В научный оборот введены десятки новых анималистических изображений, характеризующих облик художественной культуры населения раннего железного века Центрального Казахстана. Уточнена хронология элитных курганов сакской культуры Казахстана, которая по традиционному и радиоуглеродному датированию укладывается в рамки середины I тыс. до н.э. Благодаря исследованиям А. З. Бейсенова, получено более 30 радиоуглеродных дат из курганов [Beisenov et al., 2016; Бейсенов, 2016а; Бейсенов, 2018a, б].

На основании археологических материалов и радиоуглеродных данных тасмолинская культура датируется исследователем VIII-V вв. до н.э. с выделением раннего (VIII - первая половина VI в. до н.э.) и позднесакского (курганы карамолинского типа) этапов. А. З. Бейсенов отмечает, что данные по второму (среднему) этапу в силу малоизученности памятников, которых в количественном отношении меньше, чем в ранний период, не позволяют пока наполнить его реальным историческим содержанием. Период V-IV вв. до н.э. назван коргантасским, хотя, по мнению ученого, особого рассмотрения требует вопрос о памятниках IV в. до н.э., также как и проблематика хронологии курганов «с усами» [Бейсенов, 2017, с. 66].

\section{Музеефикачия Бегазы}

В 2004 г. были начаты работы по доисследованию и реставрации погребальных объектов некрополя Бегазы, которые осуществлялись под руководством А. 3. Бейсенова в течение 10 лет и завершилась публикацией монографии [Бейсенов и др., 2014]. Впервые на материалах знаковых центральноказахстанских памятников было проведено осмысление процессов сохранения, консервации, реставрации объектов эпохи древних кочевников. Музеефикация исторических памятников середины I тыс. до н.э. имела целью 
выработку современных методологических принципов консервации и реставрации памятников скифо-сакской эпохи Казахстана, что нашло практическое воплощение в активизации использования археологических памятников в историко-познавательном туризме в Казахстане. Ученый, используя выводы А. Х. Маргулана и консультации специалистов, воссоздал облик некрополя, максимально приблизив его к первоначальному и сделав аттрактивным для туристов. Было подготовлено обоснование создания заповедника-музея под открытым небом «Кызыларай-Бегазы» [Бейсенов и др., 2012]. Сегодня научный и познавательный потенциал памятников Бегазы-Кызыларайского региона активно используется в проведении экскурсионных туров в Актогайском районе Карагандинской области при посещении туристами экосайта Шабанбай-би, признанного в 2014 г., согласно результатам международного рейтинга Sustainable Destinations Global Top 100, одним из направлений устойчивого туризма в мире [Кызыларай, Интернет-ресурс].

\section{Об открытиях А. З. Бейсенова}

Знаковые объекты историкокультурного наследия Центрального Казахстана надежно ассоциируются с именем А. 3. Бейсенова. В последние десятилетия под его руководством впервые исследованы большие курганы сакского времени. Это ранее неизвестные науке захоронения сакской элиты в курганах могильников Нуркен-2, Талды-2, Карашокы, Шерубай-1, Бакыбулак, Акбеит, которые свидетельствуют о высоком уровне социально-политического устройства общества и являются источником для создания моделей, реконструиру- ющих векторы этнокультурных связей населения Центрального Казахстана с сопредельными и отдаленными регионами [Бейсенов, 2014; 2015].

Архитектурно-планиграфические особенности памятников и изучение их конструктивного оформления (сырцово-каменные конструкции) ученый сопоставляет с крупными курганами раннего железного века других регионов: так, распространение дромосных могил в Восточном и Северном Казахстане, Жетысу свидетельствует о единстве этнического массива населения и определяет значение местных племен финальной бронзы в сложении культур раннего железного века. Исследуя подземные конструкции памятников - квадратная погребальная камера из вертикальных плит, горизонтальная плиточная кладка вокруг камеры, сооружение дромоса из крупных вертикальных плит - А. 3. Бейсенов связывает с конструктивными деталями бегазинских элитных мавзолеев, делая вывод о единой линии развития культуры с эпохи поздней бронзы и преемственности бегазинской и сакской культур. По мнению исследователя, это является весомым аргументом в пользу автохтонной теории происхождения тасмолинской культуры Центрального Казахстана. Материалы погребальных сооружений дополняются результатами исследования жертвенников [Бейсенов, 2015a, б], каменных изваяний, менгиров и оленных камней [Бейсенов, 2016б; Beisenov, 2017; Бейсенов и др., 2020].

В результате раскопок сакских «царских» курганов памятника Талды-2, расположенного в долине реки Талды (Каркаралинский р-н, Карагандинская обл.), получены сенсационные материалы по сакской эпохе 
Центрального Казахстана, что вызвало широкий резонанс в мировой науке [Bejsenov, 2013]. Это является несомненной заслугой А. 3. Бейсенова, свидетельствуя о научном упорстве, трудолюбии, уверенности в успехе, стремлении к новым открытиям.

В рамках международного турне «Шествие “Золотого человека" по музеям мира» в 2019 г. сенсационные материалы могильника Талды-2 демонстрировались в синтезе с находками из курганов Иссык, Шиликты, Таксай на масштабной выставке, которая с большим успехом прошла в Сеуле, Москве, Баку, Минске, Гданьске, Ташкенте, Казани, Сиане, Скопье и др. Жителей Анкары знакомил с сакскими артефактами и А. З. Бейсенов, входивший в состав делегации РК.

Несомненной

заслугой

А. 3. Бейсенова следует признать введение в научный оборот качественно нового материала, происходящего из памятников оседлости раннего железного века и позволяющего с новых позиций подойти к изучению феномена сакской культуры. На современном этапе исследований Сарыарки этот подход наиболее последовательно реализован в работах ученого, который смог продуктивно использовать данные казахской этнографии по вопросам топографии и планиграфии кыстау, проанализировав организацию зимнего цикла хозяйствования, особенности сезонных переходов и закономерности исторического развития казахских зимников [Бейсенов, 2014a,б]. С конца 1990-х гг. на территории Сарыарки, традиционно воспринимаемой как область бытования кочевого скотоводства, было открыто свыше 50 поселенческих объектов раннего железного века [Бейсенов, 2015a; Бейсенов и др.,
2017]. Это памятники Донгал, Бугулы 1, Сарыбуйрат, Едрей, Керегетас, Карабулак, Абылай и др. продатированы временем конца эпохи бронзы и началом сакского периода - X-VIII вв. до н.э. [Бейсенов, Ломан, 2009]. К характерным признакам данных поселений А. 3. Бейсенов относит привязку к склонам возвышенностей вместо водоемов открытых долин в эпоху бронзы, малую площадь (около 10000 кв. м), слабонасыщенный культурный слой, 2-3 небольшие наземные постройки, невыразительность керамики, отражённую в орнаментации, незначительное по сравнению с эпохой поздней бронзы количество костей животных. С поселений раннего железного века получена представительная серия каменных орудий труда: мотыги, песты, зернотерки. Керамика этих поселений представляет собой промежуточный вариант между финальной бронзой и тасмолинскими традициями и имеет близкие аналогии на востоке Казахстана, в Жетысу, и далее, вплоть до районов распространения европейских скифов. Такая посуда получила название - керамика донгальского типа [Бейсенов, Ломан, 2006]. Изучение керамики позволяет назвать типологически близкие параллели - это коллекции из поселений Акмолинской области (Кеноткель-Х, Таскора, Таскора-I, исследованные экспедициями под руководством К. А. Акишева и М. К. Хабдулиной), степного Алтая, Восточного Казахстана и Жетысу.

Долгое время это направление не привлекало должного внимания исследователей, несмотря на важность этих материалов при реконструкции жизни древнего населения, связанной с бытом, хозяйственным укладом, ремеслами, а также для изучения во- 
просов не только собственно сакской археологии, но и становления кочевничества. Проделанный А. 3. Бейсеновым анализ археологических явлений на территории Центрального Казахстана в конце эпохи бронзы начале раннего железного века привел его к обоснованному убеждению, что многие изменения, произошедшие в раннем железном веке, затрагивают проблемы хозяйственно-культурного типа кочевников, цивилизационного потенциала номадов. Процесс массового накопления археологического материала по сакским поселениям, изученным А. 3. Бейсеновым, стал решающим фактором и позволил перейти к реализации структурных подходов в решении проблем хозяйственнокультурного типа ранних кочевников Центрального Казахстана, демонстрируя многоаспектный анализ сакского социума. Информативная насыщенность археологических материалов по поселенческим памятникам будет способствовать дальнейшей интенсификации палеоэкономического моделирования скифо-сакского общества.

Используя методы этноархеологии - анализ и систематизация данных по казахским зимовкам: топография и планиграфия, техника строительства, изучение вопросов их ландшафтного размещения, принципов расположения их в отношении летних стоянок - А. 3. Бейсенову удается провести широкие диахронные сопоставления и задействовать эти материалы при изучении сакских поселений. Ряд выводов исследователя непосредственно касается традиционного общества казахов [Бейсенов, 2019]. Осознавая существование на протяжении длительного периода истории определенной общности в исторических судьбах кочевников, ученый применяет опре110 деленные положения с различными допусками и для номадов раннего железного века [Бейсенов, 2015a].

Для исследователя характерно одновременное обращение к письменным, этнографическим источникам и антропологическим данным, что позволяет перепроверить и дополнить вещественные материалы. Дальнейшие исследования в этом направлении позволят на качественно ином уровне решать вопросы хронологического характера и социо-этнокультурного развития древнего населения Казахстана.

Коррелируя серию дат из поселений Сарыарки с углеродными датами из погребальных комплексов Центрального Казахстана, А. З. Бейсенов активно и целенаправленно работает над созданием общей колонки углеродных дат для всего периода раннего железного века.

Параллельно с изучением древностей Центрального Казахстана, А. 3. Бейсенов достиг определенных высот в исследовании памятников раннего железного века и Нового времени в Жетысу - это разведки и раскопки, проводившиеся на протяжении ряда лет в Кербулакском районе Алматинской области [Бейсенов и др., 2018], разведки в Аркалыкском, Амангельдинском и Джангильдинском районах Костанайской области [Бейсенов, 2019]. Успехом увенчались раскопки кургана Борсык в Атарауской обалсти [Бейсенов, Джумабекова, 2017].

Дань традищии - достойное отношение к наследию классиков

Известно, что исследование истории изучения археологических памятников Казахстана способствует формированию стратегии развития этой отрасли исторической науки, по- 
скольку позволяет выявить наиболее перспективные направления дальнейших разработок. Подобный подход рационального переосмысления ранее накопленных археологических материалов, предпринятый А. 3. Бейсеновым в процессе изучения деятельности Центрально-Казахстанской археологической экспедиции, стал основой для нового исторического знания, на котором базируются современные исследования археологов. Гипотезы и открытия А. Х. Маргулана, К. А. Акишева, М. К. Кадырбаева, А. М. Оразбаева, С. М. Ахинжанова, и др. стали достоянием науки, сыграли важную роль в ее становлении и в настоящее время служат источником открытий. А. 3. Бейсенов не случайно обращается к истории науки - это и заслуженная дань уважения признанным авторитетам казахстанской археологии, и, одновременно, свежий импульс для поисков нового, исходя из платформы фундаментальных представлений классиков. Такой подход ученого говорит в пользу его традиционного казахского воспитания, подразумевающего почтение к представителям старшего поколения и бережное отношение к их советам, консультациям, воспоминаниям, жизненным коллизиям. Стремление А. 3. Бейсенова сохранить это знание, этот бесценный архив и передать его последующим поколениям молодых ученых несомненно продвигает науку вперед, позволяя сохранить лучшие традиции, и имеет важную педагогическую составляющую - обучение студентов, магистрантов и докторантов в процессе приобретения ими профессиональных навыков.

А. 3. Бейсенову принадлежит инициатива проведения международных научно-практических конференций, в том числе, посвященной юбилейной дате Ж. Курманкулова, а также создание сборника, посвященного юбилею Б. Н. Нурмуханбетова. В предисловиях к сборникам, составленных Арманом Зияденовичем, кратко, ясно и очень образно написаны строки, зримо характеризующие как научные достижения ученых, так и их личностные качества [Бейсенов, 2011; 2013a, б]. Важным следует признать его стремление к публикации ценных источниковых материалов с целью более активного введения их в научный оборот. Примером может служить монография К. М. Карабаспаковой [2011], изданная по инициативе А. 3. Бейсенова, а также статьи юбиляра, в которых полученные результаты оперативно публикуются на страницах отечественных и зарубежных изданий.

\section{Bblводbl}

В целом, исследования А. З. Бейсенова представляют крупный вклад в историческую науку. Теоретикометодологическая ценность научных публикаций ученого состоит в осмыслении научных подходов в археологии сакской эпохи Казахстана. Научная активность А. 3. Бейсенова подтверждается многочисленными публикациями в высокорейтинговых журналах (индекс Хирша Web of Science 3, РИНЦ 14). С его открытиями археология Центрального Казахстана сделала большой шаг вперед на пути разработки новой проблематики, методов социологических реконструкций, уточнения объективности своих выводов посредством междисциплинарных исследований. Уверены, что А. З. Бейсенов плодотворно продолжит фундаментальное научное изучение древностей Казахстана. 


\section{ЛИТЕРАТУРА}

1. Археологическая карта Каркаралинского района Карагандинской области. Алматы: Иль-тех-Китап, 2004. 256 с. Коллектив авторов: Ломан В.Г., Бейсенов А.З., Евдокимов В.В., Тулеуов Т.С.

2. Археологическое наследие Центрального Казахстана: изучение и сохранение. Сб. науч. ст., посвящ. 70-летию организацииЦентрально Казахстанской археологической экспедиции Академии наук Казахстана / отв. ред. А.З. Бейсенов, В.Г. Ломан. Алматы: НИЦИА «Бегазы-Тасмола», 2017. Т. 1. 252 с.; Т. 2. 380 с.

3. Археология Казахстана в эпоху независимости: итоги, перспективы: м-ы междунар. науч. конф., посвящ. 20-летию Независимости Республики Казахстан и 20-летию Института археологии им. А.Х. Маргулана КН МОН РК (г. Алматы, 12-15 декабря 2011 г.) / гл. ред. Б.А. Байтанаев, отв. ред. А.З. Бейсенов. Алматы: Институт археологии им. А.Х. Маргулана, 2011. Т. 1.428 с.; Т. 2. 344 с.; Т. 3.328 с.

4. Бейсенов А.3. Погребальные памятники и культово-ритуальные сооружения древних номадов Центрального Казахстана (VII-I вв. до н.э.): автореф. дис. ... канд. ист. наук. Алматы: Институт археологии им. А.Х. Маргулана, 1997. 26 с.

5. Бейсенов A.3. Наш юбиляр - археолог Бекен Нурмуханбетов // Вопросы археологии Казахстана: сб. научн. ст. / отв. ред. А.З. Бейсенов. Алматы: НИЦИА «Бегазы-Тасмола», 2011. Вып. 3. С. 7-12.

6. Бейсенов А.3. От редактора // Бегазы-дандыбаевская культура Степной Евразии: сб. научн. ст., посвящ. 65-летию Ж. Курманкулова / отв. ред. А.З. Бейсенов. Алматы: НИЦИА «Бегазы-Тасмола», 2013а. С. 5-6.

7. Бейсенов А.3. Археолог Жолдасбек Курманкулов - 65 жаста! // Бегазыдандыбаевская культура Степной Евразии: сб. научн. ст., посвящ. 65-летию Ж. Курманкулова / отв. ред. А.З. Бейсенов. Алматы: НИЦИА «Бегазы-Тасмола», 2013б. C. 7-9.

8. Бейсенов А.3. Древние сокровища Сарыарки. Сарыарқаның көне жәдігерлері. Ancient Saryarka treasures. Книга-альбом. Алматы: Институт археологии им. А.Х. Маргулана, 2014а. 196 с. (на каз., рус., англ. яз.).

9. Бейсенов А.3. Об использовании данных казахской этнографии в археологических исследованиях // II Аргынбаевские чтения: м-лы Междунар. конф. (г. Алматы, 25 декабря 2014 г.). Алматы: КазНУ, 2014б. С. 87-90.

10. Бейсенов А.3. Поселения и могильники сакской эпохи Центрального Казахстана // Сакская культура Сарыарки в контексте изучения этносоциокультурных процессов Степной Евразии. Сб. научн. ст., посвящ. памяти археолога К.А. Акишева / отв. ред. А.З. Бейсенов. Алматы: НИЦИА «Бегазы-Тасмола», 2015а. С. 11-38.

11. Бейсенов A.3. Околокурганные жертвенники как разновидность памятников тасмолинской культуры // Вестник ТГУ. История. 2015б. № 4 (36). С. 96-104.

12. Бейсенов A.3. Орталық Қазақстан ерте темір дәуірі ескерткіштерін зерттеудегі көміртегілік анықтамалар // Новые методы исследования в археологии: м-лы междунар. науч.-практ. конф. (г. Алматы, 30 ноября 2016 г.). Алматы: Қазақ университеті, $2016 \mathbf{a}$. C. $13-21$.

13. Бейсенов А.З. Каменные изваяния и менгиры сакской эпохи // Вестник Хакасского ун-та им. Н.Ф. Катанова. 2016б. № 16. С. 17-22.

14. Бейсенов А.3. Тасмолинская культура Сарыарки // Казахстан в сакскую эпоху. Коллективная монография / отв. ред. А.З. Бейсенов. Алматы: Институт археологии им. А.Х. Маргулана, 2017. С. 59-96.

15. Бейсенов A.3. Тасмолинская культура Центрального Казахстана в исследованиях начала XXI века // Археологія і давня історія Украіни. 2018а. Вип. 2 (27). C. $386-396$.

16. Бейсенов А.3. Элитные курганы тасмолинской культуры Центрального Казахстана // Золото властелинов казахских степей. Совместный Каталог Республики Корея и Республики Казахстан. Астана-Сеул. 2018б. С. 68-99 (на каз., рус. яз.). 
17. Бейсенов А.З. К.А. Акишев и вопросы изучения памятников казахского времени // Маргулановские чтения - 2019: м-лы Междунар. археол. науч.-практ. конф., посвящ. 95-летию со дня рождения выдающегося казахстанского археолога К.А. Акишева (г. Нур-Султан, 19-20 апреля 2019 г.). Нур-Султан: ЕНУ им. Л.Н. Гумилева, 2019. C. $10-38$.

18. Бейсенов А.З., Ахияров И.К., Джуманазаров Н.Ш., Дуйсенбай Д.Б. Оленный камень на кургане с «усами» в долине Койшокы в Центральном Казахстане // Археологические вести. 2020. Вып. 26. С. 166-177.

19. Бейсенов А.3., Варфоломеев В.В., Касеналин А.Е. Памятники бегазыдандыбаевской культуры Центрального Казахстана. Алматы: Институт археологии им. А.Х. Маргулана, 2014. 192 с.: ил.

20. Бейсенов А.З., Джумабекова Г.С. О древнем ритуале порчи предметов, используемых в обряде погребения кочевников // Поволжская археология. 2017. № 2 (20). C. $28-46$.

21. Бейсенов А.З., Джумабекова Г.С., Базарбаева Г.А. Искусство саков Сарыарки. Алматы: Институт археологии им. А.Х. Маргулана, 2015. 168 с.: ил.

22. Бейсенов А.З., Дуйсенбай Д.Б., Китов Е.П., Кулькова М.А. Исследование сакских курганов в урочище Каспан в Жетысу // ТиПАИ. 2018. Т. 23. № 3. С. 138-162. DOI: https://doi.org/10.14258/tpai(2018)3(23).-10

23. Бейсенов А.З., Исмагулова А.О., Китов Е.П., Китова А.О. Население Центрального Казахстана в I тыс. до н.э. Алматы: Институт археологии им. А.Х. Маргулана, 2015. 188 с.

24. Бейсенов А.З., Ломан В.Г. Вопросы изучения поселений раннего железного века Центрального Казахстана // Известия НАН РК. Сер. обществ. наук. 2006. № 1 (252). С. 36-44.

25. Бейсенов А.3., Ломан В.Г. Древние поселения Центрального Казахстана. Алматы: Институт археологии им. А.Х. Маргулана, 2009. 264 с.

26. Бейсенов А.З., Мусаева Р.С., Жамбулатов К.А. О создании естественнонаучного обоснования проектируемого заповедника-музея «Кызыларай-Бегазы» // Археология и история Сарыарки: сб. научн. ст. Караганда: КарГУ им. Е. Букетова, 2012. С. 259-275.

27. Бейсенов А.З., Хаврин С.В. Металлические изделия тасмолинских памятников Центрального Казахстана // Известия Самарского научного центра РАН. 2015. Т. 17. № 3. Ч. 2. С. 526-531.

28. Бейсенов А.З., Шульга П.И., Ломан В.Г. Поселения сакской эпохи. Алматы: НИЦИА «Бегазы-Тасмола», 2017. 208 с.

29. Восточная Сарыарка. Каркаралинский регион в прошлом и настоящем. / под ред. К.С. Алдажуманова, А.З. Бейсенова. Алматы: Эверо, 2004. 564 с.: ил.

30. Джумабекова Г.С., Базарбаева Г.А. Художественные бронзы Жетысу. Алматы: Институт археологии им. А.Х. Маргулана, 2013. 120 с.

31. Ермолаева А.С. Памятники предгорной зоны Казахского Алтая (эпоха бронзы - раннее железо). Алматы: Институт археологии им. А.Х. Маргулана, 2012. 218 с.

32. История Каркаралы в документах и материалах. Т. 1. Каркаралинский внешний округ / сост. А.З. Бейсенов, М.Г. Жылысбаева, И.М. Самигулин, Д.Ж. Турсынбаев. Алматы: Інжу-Маржан полиграфия, 2008, 494 с.

33. История Каркаралы в документах и материалах. Т. 2. Каркаралинский внешний округ / сост. А.З. Бейсенов, М.Г. Жылысбаева, Г.М. Каратаева, Р.Е. Оразов, Д.Ж. Турсынбаев. Алматы: Інжу-Маржан полиграфия, 2009, 508 с.

34. Кадырбаев М.К. Памятники тасмолинской культуры // Маргулан А.Х., Акишев К.А., Кадырбаев М.К., Оразбаев А.М. Древняя культура Центрального Казахстана. Алма-Ата: изд-во «Наука» АН КазССР, 1966. С. 303-433.

35. Карабаспакова К.М. Жетысу и Южный Казахстан в эпоху бронзы. Алматы: НИЦИА «Бегазы-Тасмола», 2011. 220 с. 
36. Кызыларай: высота и древность. URL:http://www.outfitter.kz/tury-na-prirodu/ karagandinskaya/20-kyzylaraj-vysota-i-drevnost (дата обращения 07.11.2020)

37. Рудковский И.В. Андроновская орнаментика в контексте системообразующих инвариантов. Алматы: Институт археологии им. А.Х. Маргулана, 2013. 189 с.

38. Сакская культура Сарыарки в контексте изучения этносоциокультурных процессов степной Евразии. Тез. докл. Круглого стола, посвящ. 20-летию Независимости Республики Казахстан (г. Караганды, 23-25 ноября 2011 г.) / отв. ред. А.З. Бейсенов. Караганды: НИЦИА «Бегазы-Тасмола», 2011. 218 с.

39. Смаилов Ж.Е., Бейсенов А.З. Исследование Кызылкентского дворца в Центральном Казахстане// Некоторые вопросы истории Казахстана: сб. научн. ст. Жезказган: Жезказганский университет, 1996. С. 58-67.

40. Смаилов Ж.Е., Бейсенов А.З. Кызылкентский дворец (Кыз Аулие) / Восточная Сарыарка. Каркаралинский регион в прошлом и настоящем. Алматы: Эверо, 2004. C. 254-269.

41. Свидетели тысячелетий: археологическая наука Казахстана за 20 лет (19912011): сб. науч. ст. / гл. ред. Б.А. Байтанаев, отв. ред. А.З. Бейсенов. Алматы: Институт археологии им. А.Х. Маргулана, 2011. 448 с.: ил.

42. Bejsenov A. Die nekropole Taldy-2 in beziehung zu den kulturen der fruhsakishen zeit osteurasiens // Unbekanntes Kasachstan. Archaolgie im Herzen Asiens. T. II [Catalogue of the exhibition] / Ed. by Z. Samashev and T. Stoellner. Bochum, 2013. P. 595-608.

43. Beisenov A.Z., Duisenbai D., Akhiyarov I., Sargizova G. Dromos burials of Tasmola Culture in Central Kazakhstan // Anthropologist. 2016. Vol. 26, Issue 1-2. P. 25-33.

44. Beisenov A. Z., Kassenalin A.E., Zhambulatov K. A., Duisenbai D., Svyatko S.V., Reimer P.J. First Radiocarbon Chronology for the Early Iron Age Sites of Central Kazakhstan (Tasmola Culture and Korgantas Period) // Radiocarbon. 2016. 58. P. 179-191. doi:10.1017/ RDC.2015.18.

45. Beisenov A. Z. Tasmola culture. Stone sculptures and menhirs // История и археология Турана [History and archeology of Turan]. 2017. № 3. Р. 59-66.

\section{REFERENCES}

1. Loman, V. G., Beisenov, A. Z., Evdokimov, V. V., Tuleuov, T. S. 2004. Arheologicheskaya karta Karkaralinskogo rayona Karagandinskoy oblasti (Archaeological map of the Karkaraly district of the Karaganda region). Almaty: Il-tekh-Kitap (in Russian).

2. Beisenov, A. Z., Loman, V. G. (eds.). 2017. Arheologicheskoe nasledie Centralnogo Kazahstana: izuchenie i sohranenie (Archaeological heritage of Central Kazakhstan: study and preservation). Almaty: "Begazy-Tasmola", T. 1; T. 2 (in Kazakh, Russian).

3. Baianayev, B. A., Beisenov, A. Z. (eds.). 2011. Arheologiya Kazahstana v epohu nezavisimosti: itogi, perspektivy (Archeology of Kazakhstan in the era of independence: results, prospects). Almaty: A.Kh. Margulan Institute of Archeology. T. 1; T. 2; T. 3 (in Kazakh, Russian, English).

4. Beisenov, A. Z. 1997. Pogrebalnye pamyatniki i kultovo-ritualnye sooruzheniya drevnih nomadov Centralnogo Kazahstana (VII-I vv. do n.e.) (Burial monuments and cultritual structures of the ancient nomads of Central Kazakhstan $\left(7^{\text {th }}-1^{\text {st }} c . B C\right)$ : thesis of the Cand. Hist. sc. Almaty: A.Kh. Margulan Institute of Archeology (in Russian).

5. Beisenov, A. Z. 2011. In: Beisenov, A. Z. (ed.). Voprosy arheologii Kazahstana (Questions of archeology of Kazakhstan), 3, 7-12. Almaty: "Begazy-Tasmola" Publ. (in Russian).

6. Beisenov, A. Z. 2013a. In: Beisenov, A. Z. (ed.). Begazy-dandybaevskaya kultura Stepnoy Evrazii (Begazy-Dandybay culture of Steppe Eurasia). Almaty: "Begazy-Tasmola" Publ., 5-6 (in Russian).

7. Beisenov, A. Z. 2013b. In: Beisenov, A. Z. (ed.). Begazy-dandybaevskaya kultura Stepnoy Evrazii (Begazy-Dandybay culture of Steppe Eurasia). Almaty: "Begazy-Tasmola" Publ., 7-9 (in Kazakh). 
Бедельбаева М.В., Базарбаева Г.А. Per aspera ad astra: к юбилею Армана Бейсенова

8. Beisenov, A. Z. 2014a. Ancient Saryarka treasures. Almaty: A.Kh. Margulan Institute of Archeology (in Kazakh, Russian, English).

9. Beisenov, A. Z. 2014b. In: II Argynbaevskie chteniya (2nd Argynbayev readings). Almaty: Kazakh National University Publ., 87-90 (in Russian).

10. Beisenov, A. Z. 2015a. In: Beisenov, A. Z. (ed.). Sakskaya kultura Saryarki v kontekste izucheniya etnosociokulturny processov Stepnoy Evrazii (Sak culture of Saryarka in the context of studying the ethnosocial and cultural processes of Steppe Eurasia). Almaty: "Begazy-Tasmola" Publ., 11-38 (in Russian).

11. Beisenov, A.Z. 2015b. In Vestnik TGU. Istoriya (Tomsk State University Bulletin. History), 4 (36), 96-104 (in Russian).

12. Beisenov, A. Z. 2016a. In: Novye metody issledovaniya v arheologii (New research methods in archeology). Almaty: Kazakh University Publ., 13-21 (in Kazakh).

13. Beisenov, A. Z. 2016b. In: Vestnik Hakasskogo un-ta im. N.F. Katanova (Bulletin of the N.F. Katanov Khakass University), 16, 17-22 (in Russian).

14. Beisenov, A. Z. 2017. In: Beisenov, A. Z. (ed.). Kazahstan v sakskuyu epohu (Kazakhstan in the Sak epoch). Collective monograph. Almaty: A.Kh. Margulan Institute of Archeology, 59-96 (in Russian).

15. Beisenov, A. Z. 2018a. In: Arheologiya i davnya istoriya Ukraini (Archeology and Early history of Ukraine), 2 (27), 386-396 (in Russian).

16. Beisenov, A. Z. 2018b. In: Zoloto vlastelinov kazahskih stepey (Gold of the rulers of the Kazakh steppes). Astana-Seoul, 68-99 (in Kazakh, Russian).

17. Beisenov, A. Z. 2019. In: Margulanovskie chteniya - 2019 (Margulan readings 2019). Nur-Sultan: L.N. Gumilyov Eurasian National University Publ., 10-38 (in Russian).

18. Beisenov, A. Z., Akhiyarov, I. K., Jumanazarov. N. Sh., Duysenbai, D. B. 2020. In: Arheologicheskie vesti (Archeological news), 26, 166-177 (in Russian).

19. Beisenov, A. Z., Varfolomeev, V. V., Kasenalin, A. E. 2014. Pamyatniki begazydandybaevskoy kultury Centralnogo Kazahstana (Monuments of the Begazy-Dandybay culture of Central Kazakhstan). Almaty: A.Kh. Margulan Institute of Archeology (in Russian).

20. Beisenov, A. Z., Jumabekova, G. S. 2017. In: Povolzhskaya arheologiya (The Volga river region archeology), 2 (20), 28-46 (in Russian).

21. Beisenov, A. Z., Jumabekova, G. S., Bazarbayeva, G. A. 2015. Iskusstvo sakov Saryarki (The art of the Saka tribes of Saryarka). Almaty: A.Kh. Margulan Institute of Archeology (in Russian).

22. Beisenov, A. Z., Duysenbai, D. B., Kitov, E. P., Kulkova, M. A. 2018. In: Teoriya i praktika arheologicheskih issledovaniy (Theory and practice of archaeological research), 3 (23), 138-162. DOI: https://doi.org/10.14258/tpai(2018)3(23).-10 (in Russian).

23. Beisenov, A. Z., Ismagulova, A. O., Kitov, E. P., Kitova, A. O. 2015. Naselenie Centralnogo Kazahstana v I tys. do n.e. (Population of Central Kazakhstan in the 1st millennium BC). Almaty: A.Kh. Margulan Institute of Archeology (in Russian).

24. Beisenov, A. Z., Loman, V. G. 2006. In: Izvestiya NAN RK. Ser. obshchestv. nauk (Bulletin of NAS RK. Social Science Series), 1 (252), 36-44 (in Russian).

25. Beisenov, A.Z., Loman, V. G. 2009. Drevnie poseleniya Centralnogo Kazahstana (Ancient settlements of Central Kazakhstan). Almaty: A.Kh. Margulan Institute of Archeology (in Russian).

26. Beisenov, A. Z., Musaeva, R. S., Jambulatov, K. A. 2012. In: Arheologiya $i$ istoriya Saryarki (Archeology and history of Saryarka). Karaganda: E. Buketov Karaganda State University Publ., 259-275 (in Russian).

27. Beisenov, A. Z., Khavrin, S. V. 2015. In: Izvestiya Samarskogo nauchnogo centra RAN (Bulletin of the Samara Scientific Centre of the Russian Academy of Sciences), 3 (17), 526-531 (in Russian).

28. Beisenov, A. Z., Shulga, P. I., Loman, V. G. 2017. Poseleniya sakskoy epokhi (Settlements of the Saka era). Almaty: "Begazy-Tasmola" Publ. (in Russian).

29. Aldajumanov, K. S., Beisenov, A. Z. (eds.). 2004. Vostochnaya Saryarka. Karkaralinskiy region v proshlom i nastoyashchem (Eastern Saryarka. Karkaraly region in the past and present). Almaty: "Evero" (in Russian). 
30. Jumabekova, G. S., Bazarbayeva, G. A. 2013. Hudozhestvennye bronzy Zhetysu (The Bronze Art of Jetysu). Almaty: A.Kh. Margulan Institute of Archeology (in Russian).

31. Ermolaeva, A. S. 2012. Pamyatniki predgornoy zony Kazahskogo Altaya (epoha bronzy - rannee zhelezo) (The monuments of the foothill zone of the Kazakh Altay (Bronze and Early Iron Age). Almaty: A.Kh. Margulan Institute of Archeology (in Russian).

32. Beisenov, A. Z., Zhylysbayeva, M. G., Samigulin, I. M., Tursynbayev, D. Zh. (compl.). 2008. Istoriya Karkaraly v dokumentah i materialah. T. 1. Karkaralinskiy vneshniy okrug (History of Karkaraly in documents and materials. T. 1. Karkaralinsky outer district). Almaty: "Inzhu-Marzhan" Publ. (in Russian).

33. Beisenov, A. Z., Zhylysbayeva, M. G., Karataeva, G. M., Orazov, R. E., Tursynbayev, D. Zh. (compl.). 2009. Istoriya Karkaraly $v$ dokumentah i materialah. T. 2. Karkaralinskiy vneshniy okrug (History of Karkaraly in documents and materials. T. 2. Karkaralinsky outer district). Almaty: "Inzhu-Marzhan” Publ. (in Russian).

34. Kadyrbayev, M. K. 1966. In: Margulan, A.Kh., Akishev, K. A., Kadyrbayev, M. K., Orazbayev, A. M. Drevnyaya kultura Centralnogo Kazahstana (Ancient culture of Central Kazakhstan). Alma-Ata: "Nauka" Publ., 303-433 (in Russian).

35. Karabaspakova, K. M. 2011. Zhetysu i Yuzhnyi Kazahstan v epohu bronzy (Zhetysu and South Kazakhstan in the Bronze Age). Almaty: "Begazy-Tasmola" (in Russian).

36. Kyzylaray: vysota i drevnost (Kyzylarai: height and antiquity). URL: http://www. outfitter.kz/tury-na-prirodu/karagandinskaya/20-kyzylaraj-vysota-i-drevnost

37. Rudkovskiy, I. V. 2013. Andronovskaya ornamentika v kontekste sistemoobrazuyushchih invariantov (Andronovo ornamentation in the context of systemforming invariants). Almaty: A.Kh. Margulan Institute of Archeology(in Russian).

38. Beisenov, A. Z. (ed.) 2011. Sakskaya kultura Saryarki v kontekste izucheniya etnosociokulturnyh processov stepnoy Evrazii (Saka culture of Saryarka in the context of studying the ethnosocial and cultural processes of Steppe Eurasia). Karagandy: "BegazyTasmola" (in Kazakh, Russian).

39. Smailov, Zh. E., Beisenov, A. Z. 1996. In: Nekotorye voprosy istorii Kazahstana (Some questions of the history of Kazakhstan). Zhezkazgan: Zhezkazgan University Publ., 58-67 (in Russian).

40. Smailov, Zh. E., Beisenov, A.Z. 2004. In: Vostochnaya Saryarka. Karkaralinskiy region $v$ proshlom $i$ nastoyashchem (Eastern Saryarka. Karkaraly region in the past and present). Almaty: "Evero" Publ., 254-269 (in Russian).

41. Baitanayev, B. A., Beisenov, A. Z. (eds.). 2011. Svideteli tysyacheletiy: arheologicheskaya nauka Kazahstana za 20 let (1991-2011) (Witnesses of millennia: archaeological science of Kazakhstan for 20 years (1991-2011)). Almaty: A.Kh. Margulan Institute of Archeology (in Kazakh, Russian).

42. Beisenov, A. 2013. In: Samashev, Z. and Stoellner, T. (eds.). Unbekanntes Kasachstan. Archaolgie im Herzen Asiens. T. II [Catalogue of the exhibition]. Bochum, 595-608.

43. Beisenov, A. Z., Duysenbai, D., Akhiyarov, I., Sargizova, G. 2016. In: Anthropologist, 1-2 (26), 25-33.

44. Beisenov, A. Z., Kassenalin, A. E., Zhambulatov, K. A., Duysenbai, D., Svyatko, S. V., Reimer, P. J. 2016. In: Radiocarbon, 58, 179-191. doi:10.1017/RDC.2015.18.

45. Beisenov, A. Z. 2017. In: Istoriya i arheologiya Turana [History and archeology of Turan], 3, 59-66.

Мақала туралы ақпарат / Информация о статье / Information about the article.

Жариялауға қабылданды / Принята к публикации / Accepted for publication: 14.09.2020. 